\title{
Energie sparen in Powerwash-Anlagen
}

\begin{abstract}
Ein neuer Spritzreiniger für die Oberflächenreinigung von Kunststoffteilen erreicht die geforderte Sauberkeit schon bei Raumtemperatur und reduziert so den Energieaufwand in Powerwash-Anlagen erheblich.
\end{abstract}

Vor dem Lackieren von Kunststoffteilen müssen die Werkstücke gereinigt und vorbehandelt werden. Die Sauberkeit der Teileoberfläche ist entscheidend für ein optimales Ergebnis in der Lackierung. In Powerwash-Anlagen werden die Kunststoffteile, beispielsweise Stoßfänger, mit einer wässrigen Reinigerlösung bei Temperaturen von üblicherweise 45 bis $70^{\circ} \mathrm{C}$ mittels Spritzanwendung behandelt. Die hohen Temperaturen sind notwendig, um hartnäckige Verschmutzungen $\mathrm{zu}$ lösen und die Bäder schaumarm zu halten, was Überschäumen sowie unnötigen Wartungsaufwand verhindert.

Moderne Lackieranlagen laufen in der Regel 24 Stunden, 7 Tage die Woche im Dauerbetrieb. Auch in der Vorbehandlung muss die Prozesstemperatur deshalb dauerhaft hoch bleiben. Das verursacht jedoch enorme Energiekosten.

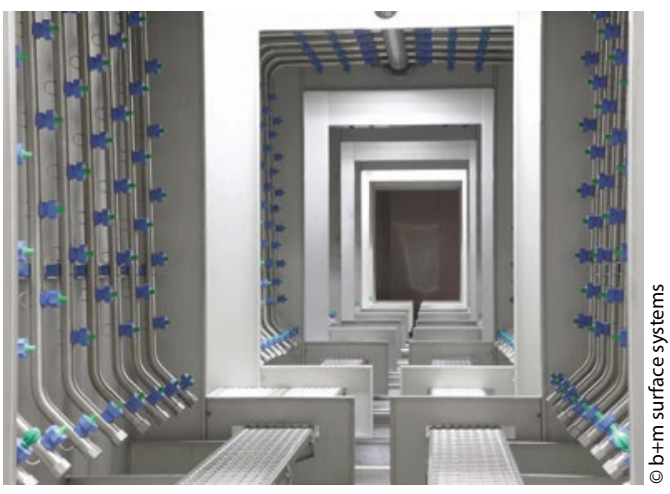

In Powerwash-Anlagen werden Kunststoffteile mit einer wässrigen Reinigerlösung bei Temperaturen von üblicherweise 45 bis $70^{\circ} \mathrm{C}$ mittels Spritzanwendung behandelt.

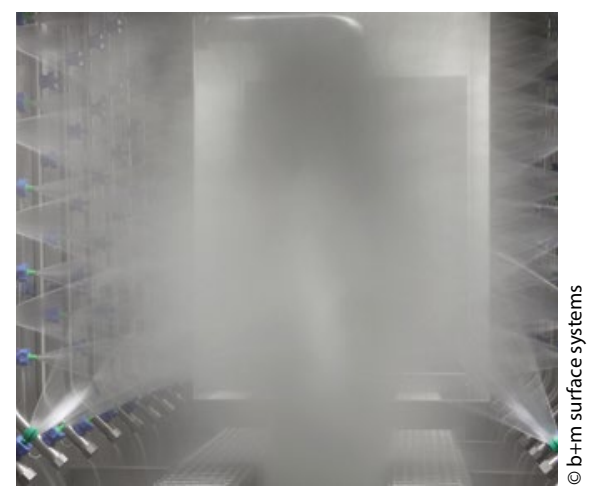

Der neue Spritzreiniger reduziert den Energieaufwand für Powerwash-Anlagen deutlich, da er schon bei Raumtemperatur die erforderliche Reinigungsleistung erreicht.
Für die Vielzahl von Anwendungen stehen verschiedene alkalische und saure Reiniger zur Auswahl - teilweise komplett kennzeichnungsfrei. Der Spritzreiniger eignet sich für alle gängigen Kunststoffe,

\section{Optimale Ergebnisse bei niedrigen Temperaturen}

Mit dem neuen Spritzreiniger Divinol $1362 \mathrm{KC}$ von Zeller + Gmelin kann beim Energieeinsatz erheblich gespart werden, da der prozessstabile Reiniger die geforderte Oberflächensauberkeit bereits bei reduzierten Badtemperaturen von $25^{\circ} \mathrm{C}$ erreicht. Das notwendige Aufheizen und durchgängige Halten von hohen Prozesstemperaturen entfallen. Die Vorbehandlung und somit die gesamte Lackierung werden wirtschaftlicher.

Eine niedrige Vorbehandlungstemperatur bringt zahlreiche Vorteile mit sich.

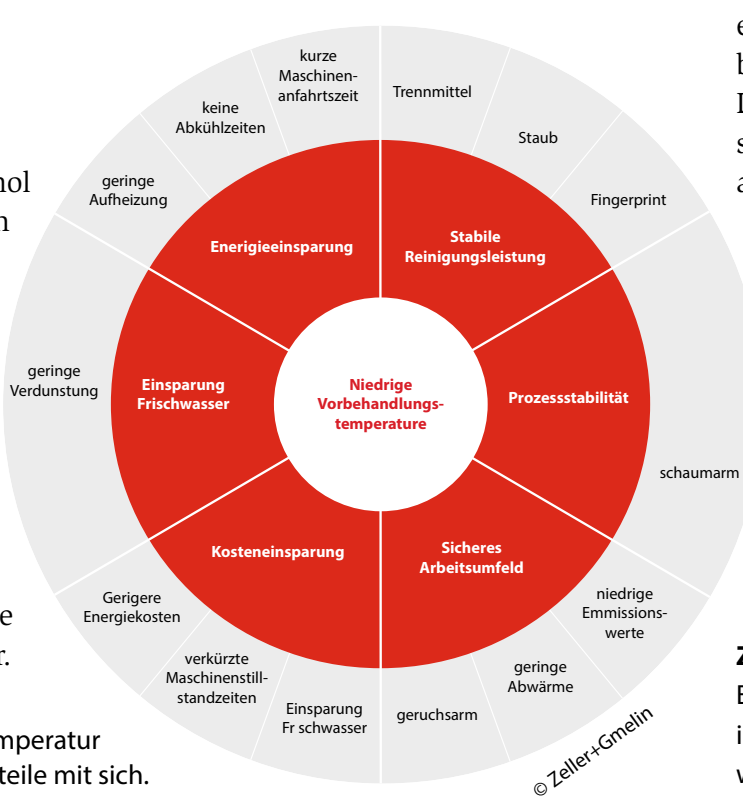

verfügt über eine hohe Biostabilität und kommt ohne Biozide aus. Er kann ohne störende Schaumbildung eingesetzt werden. Aufgrund der niedrigen Prozesstemperatur verdunstet im Betrieb der Powerwash-Anlage weniger Wasser, was auch eine Einsparung beim Frischwasserverbrauch bewirkt.

Das Thema Nachhaltigkeit und Klimaschutz hat bei dem Traditionsunternehmen aus Eislingen einen hohen Stellenwert. Im Januar 2020 hat sich Zeller + Gmelin als „Klimaneutraler Standort“ qualifiziert. Alle Produkte - auch der neue Spritzreiniger - werden klimaneutral produziert, gelagert und ausgeliefert. //

\section{Kontakt}

Zeller+Gmelin GmbH \& Co. KG Eislingen/Fils info@zeller-gmelin.de www.zeller-gmelin.de 